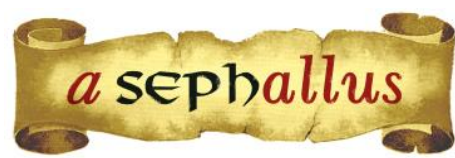

Revista aSEPHallus de Orientação Lacaniana

Núcleo Sephora de Pesquisa sobre o Moderno e o Contemporâneo

ISSN 1809 - $709 \mathrm{X}$

\title{
Psicanálise aplicada à instituição: a prática clínica no hospital geral ${ }^{1}$
}

Manuella Itapary Ribeiro Moreira

Orcid: https://orcid.org/ 0000-0002-3068-8905

Bacharel em Psicologia pela Pontifícia Universidade Católica do Rio de Janeiro / PUC Rio de Janeiro, Brasil). Mestre em Teoria Psicanalítica pela Universidade Federal do Rio de Janeiro / UFRJ (Rio de Janeiro, Brasil). Membro Associado do Instituto Sephora de Ensino e Pesquisa de Orientação Lacaniana / ISEPOL (Rio de Janeiro, Brasil). Integrante do projeto de extensão "Psicanálise aplicada à prática do psicólogo no hospital" / PPGTP-UFRJ (Rio de Janeiro, Brasil). E-mail: manuitapary@hotmail.com

Tania Coelho dos Santos Orcid: https://orcid.org/0000-0002-5360-7864 Pós-doutorado no Departamento de Psicanálise de Paris VIII (Paris, França) Professor Associado, nível IV no Programa de Pós-graduação em Teoria Psicanalítica / UFRJ (Rio de Janeiro, Brasil)

Pesquisadora do CNPQ nível $1 \mathrm{C}$ Presidente do Instituto Sephora de Ensino e Pesquisa de Orientação Lacaniana / ISEPOL (Rio de Janeiro, Brasil)

Psicanalista Membro da École de La Cause Freudienne (Brasil) Membro da Escola Brasileira de Psicanálise e da Associação Mundial de Psicanálise (Paris, França) Membro da Associação Universitária de Pesquisa em Psicopatologia Fundamental (Rio de Janeiro, Brasil)

E-mail: taniacs@openlink.com.br

Resumo: A psicanálise aplicada à instituição hospitalar ensina sobre a particularidade do caso, o diagnóstico e tratamento da urgência subjetiva de um sujeito ou de seus familiares diante de uma doença grave. No ambiente hospitalar são desencadeadas reações emocionais mais ou menos agudas como resposta subjetiva ao encontro com o desamparo e a fragilidade do corpo. As diretrizes desse trabalho clínico-institucional foram lançadas sob coordenação de Fernanda Saboya e supervisão da Prof. Tania Coelho dos Santos e sua prática faz parte do projeto de psicanálise aplicada do Instituto Sephora de Ensino e Pesquisa de Orientação Lacaniana.

Palavras-chave: Psicanálise Aplicada; Hospital; Desamparo; Narcisismo; Luto.

La psychanalyse appliquée à l'institution : la pratique clinique à l'hôpital général: La psychanalyse appliquée a l' institution hospitalière nous démontre la particularité de chaque cas et l'urgence subjective par rapport au diagnostic et au traitement d'une maladie grave. Dans le contexte hospitalier nous avons observé des réactions émotionnelles diverses, comme réponse subjective a la rencontre de l'impuissance et de la fragilité du corps. Les directives de travail clinique-institutionel ont été lancées sous la coordination de Fernanda Saboya et supervision de la Prof. Tania Coelho dos Santos e sa pratique fait partie du projet de psychanalyse apliquée de I'Institut Sephora pour I'Enseignement et la Recherche d'Orientation Lacanienne.

Mots clés: Psychanalyse Appliquée; Hôpital; Impuissance; Narcissisme; Deuil.

Psychoanalysis applied to the institution: clinical practice in the general hospital: The application of psychoanalysis to the hospital institution demonstrates the particularity of each case and the subjective urgency that arises when facing the diagnosis and treatment of a serious illness. In the hospital environment 
Revista aSEPHallus de Orientação Lacaniana

Núcleo Sephora de Pesquisa sobre o Moderno e o Contemporâneo

ISSN $1809-709$ X

we observe several different emotional reactions as subjective responses to the encounter with helplessness and the fragility of the body. The guidelines of this institutional clinical work were released under the coordination of Fernanda Saboya and supervision of Prof. Tania Coelho dos Santos and the practice is part of the psychoanalysis project applied to the Sephora Institute of Teaching and Research of Lacanian Orientation. Keywords: Applied Psychoanalysis; Hospital; Helplessness; Narcissism; Mourning. 
Revista aSEPHallus de Orientação Lacaniana

Núcleo Sephora de Pesquisa sobre o Moderno e o Contemporâneo ISSN $1809-709$ X

\section{Psicanálise aplicada à instituição: a prática clínica no hospital geral}

Manuella Itapary Ribeiro Moreira \& Tania Coelho dos Santos

\section{O psicanalista diante do impacto psicológico do adoecer}

Abordaremos a experiência clínica-institucional de um serviço de psicologia inserido na rotina da Unidade de Terapia Intensiva (UTI), no setor destinado ao atendimento do paciente grave, que necessita de tratamento diuturno, contínuo e com alto grau de complexidade e vigilância, em um hospital privado, localizado na Zona Sul da cidade do Rio de Janeiro. Na UTI a equipe é multidisciplinar, constituída por médicos intensivistas, enfermeiros e técnicos de enfermagem, que recebem o apoio de profissionais como psicólogos, fisioterapeutas, fonoaudiólogos, nutricionistas e outros.

A UTI é um setor que recebe grandes investimentos em tecnologia e treinamento de pessoas, uma vez que é reservado aos pacientes mais graves. $O$ tratamento de uma doença aguda impõe ao doente um encontro mais difícil com a fragilidade do próprio corpo e suas limitações. Alguns pacientes correm riscos psicológicos em consequência da internação hospitalar em UTI: doença mais letal, stress psicológico agudo em consequência do sofrimento corporal derivado de tratamentos mais invasivos (sonda nasogástrica ${ }^{2}$, sonda urinária ${ }^{3}, \mathrm{PICC}^{4}, \mathrm{GTT}^{5}$ e $\mathrm{IOT}^{6}$ etc.), sofrimento psicológico extremo que pode levar a uma síndrome de confinamento (delirium ${ }^{7}$ ), alterações abruptas do humor e/ou do comportamento, possíveis conflitos acentuados com a equipe e graves distúrbios do sono. Por esse motivo, é preciso que estejamos muito bem inseridos na rotina da unidade de terapia intensiva e devemos participar ativamente da discussão dos casos por meio do round ${ }^{8}$ multidisciplinar. É uma rotina mais intensa do que em qualquer outro setor do hospital e nos exige uma imersão muito maior para a identificar com agilidade as demandas da equipe multidisciplinar, do paciente e de sua família.

O trabalho consiste primordialmente em acolher e tratar a urgência subjetiva do paciente e de sua família. Geralmente, isso acontece durante o horário de visitas estipulado pelo hospital. Dessa forma, é possível recolher as principais manifestações emocionais, identificar a urgência subjetiva caso a caso e, sempre que possível, aprofundar o diagnóstico estrutural do paciente. Os significantes que aparecem nas entrevistas com a família servem de ferramenta para a identificação da estrutura subjetiva do paciente internado. Construir a lógica subjetiva do caso, para além do adoecimento físico, é essencial a nossa estratégia para acompanhá-lo durante todo o processo de recuperação e, muitas vezes, depois do período de internação. Deste modo, não tomamos o caso na perspectiva da psicologia hospitalar. Não se trata de acolher o sofrimento de um indivíduo adoecido. Trata-se de abordar o sujeito do inconsciente e seus sintomas, através da psicanálise aplicada, admitindo que o impacto do adoecer não é o mesmo nas diferentes neuroses e psicoses. Estar presente no horário da visita familiar permite oferecer um espaço para a fala por meio da oferta simultânea de uma escuta que valoriza a nomeação da particularidade do mal- 
estar, considerando a história de um sujeito e de sua família antes do desencadeamento da doença. Procuramos recolher informações que auxiliem na percepção da cultura familiar, identificar os diferentes elementos e que papéis desempenham, avaliar a qualidade do relacionamento intersubjetivo entre eles e, sobretudo, situar que lugar o paciente ocupa na dinâmica familiar. Procuramos precisar qual será o impacto sobre os familiares de um evento adverso como óbito ou invalidez permanente. Esses são pontos imprescindíveis na construção de uma hipótese psicodiagnóstica acerca dos sintomas de um sujeito e de seus parceiros.

Para a psicanálise, o diagnóstico se constitui a partir da lógica do inconsciente e de seu estatuto em relação à realidade. $O$ que a psicanálise nos ensina é que toda a relação do sujeito com a realidade é mediada pela realidade psíquica. A formulação inédita acerca do inconsciente é desenvolvida no texto inaugural $A$ interpretação dos sonhos, em que Freud (1900[1969]) postula: "O inconsciente é a verdadeira realidade psíquica (...) em sua natureza interior é tão desconhecida para nós quanto a realidade do mundo externo, e se apresenta de modo tão incompleto pelos dados da consciência quanto o mundo externo pelas comunicações dos sentidos)" (p.613).

Isso significa dizer que o mundo interno e externo são ambos exteriores à nossa capacidade de apreensão, no sentido mesmo da percepção, que só pode ser alcançada parcialmente. Portanto, a realidade psíquica não se reduz à diferenciação ego-realidade, mundo interno e mundo externo, embora inclua essa diferença. A sua fonte primária é o inconsciente que, em sua dimensão desconhecida e inalcançável na sua totalidade, emerge mesmo assim através da fala, sonhos, chiste, ato falho e sintomas. 0 inconsciente é um dizer que transparece entre os ditos de um sujeito no dispositivo analítico. Na prática da psicanálise aplicada no hospital, é preciso inventar permanentemente estratégias que nos permitam fazer emergir na fala do paciente esse dizer inconsciente. A psicanálise aplicada ao campo da saúde e do hospital nos exige evitar que o sujeito seja reduzido ao paciente adoecido, apenas um corpo doente ora perturbado, ora incompreensível ou mudo.

Quando avaliamos um caso de urgência subjetiva no ambiente hospitalar precisamos considerar o campo do sofrimento psíquico, e só podemos fazê-lo através do que aparece por meio de palavras e ações. A essas manifestações é preciso atribuir uma significação particular, evitando reduzir o paciente ao discurso médico que capta a dimensão típica do caso: o enfartado cardíaco, o enfizematoso paciente peneumológico, o renal, o hepático, o trombofílico, o hipertenso, o diabético. Procuramos devolver a cada um sua particularidade enquanto sujeito. Procuramos apreender a realidade única à qual ele responde, a partir da qual ele se vê, fala, pensa, sofre, estranha, interroga, questiona e se posiciona no mundo. A realidade psíquica envolve uma dimensão de alteridade, porque o sujeito se constitui a partir da relação com o Outro ${ }^{9}$, ego-Outro, nos primórdios do desenvolvimento subjetivo. Por considerar a realidade do inconsciente como discurso do Outro, o psicanalista opera pela via da transferência ${ }^{10}$, e os instrumentos de diagnóstico e tratamento estão marcados por essas concepções freudianas. 
A situação de adoecimento pode provocar reações emocionais intensas e potencialmente desorganizadoras em alguns pacientes e em seus familiares também. $O$ saber psicanalítico se interessa por essas manifestações subjetivas, uma vez que a escuta do sofrimento do sujeito se decifra por meio da suposição de que há um saber em jogo, uma realidade psíquica que não se reduz à realidade social compartilhada. Para além do saber médico e da verdade da ciência, a prática da psicanálise se orienta pela verdade do sujeito e pelos fenômenos psíquicos que se manifestam cifrados através de reações emocionais particulares na situação de doença. Portanto, na prática do psicanalista inserido no contexto hospitalar, o diagnóstico remete à dimensão estrutural da vida psíquica não se reduzindo jamais a um mero acontecimento no campo da saúde. O diagnóstico estrutural é levantado como hipótese a respeito do sofrimento subjetivo, a partir da fala dirigida ao psicanalista como alguém capaz de ouvir a lógica do inconsciente.

\section{As respostas subjetivas frente ao desamparo: traumatismo e defesas psíquicas}

Na prática clínica no hospital geral, ao observar sujeitos acometidos por uma doença grave, destituídos de recursos simbólicos suficientes para lidar com a situação de perda, somos levados a refletir sobre a teoria freudiana acerca do desamparo ${ }^{11}$. O ser humano nasce pequeno e desamparado, fato que the impõe um traumatismo de nascimento, isto é, um despreparo que nos obriga a uma dependência extrema do Outro. Esse vínculo primordial é essencial e constitutivo do sujeito do inconsciente. Das marcas resultantes do processo de indiferenciação com esse Outro e separação dele, resultará aquilo que temos nomeado até esse momento como estrutura subjetiva. Antes que o sujeito seja capaz de falar, ele é falado pelo Outro. $O$ inconsciente é o discurso do Outro. $\mathrm{O}$ eu, como instância unificadora, constitui-se só depois por meio de uma identificação ao Outro que the permite reunir suas experiências parciais em torno dele. $\mathrm{O}$ encontro com a doença, portanto, com o limite da vida, pode despertar antigas marcas dessas experiências de desamparo e desencadear defesas primitivas relacionadas aos traumas de nascimento, desamparo primordial e às perdas e traumas posteriores.

De fato, o trauma que o homem experimenta no nascimento repete-se em experiências posteriores como privação, frustração e castração. Desde esse primeiro momento, o sujeito não é somente separado da mãe, mas também perde uma parte de si mesmo. Daí em diante, ele se caracteriza como um ser incompleto, ferido, dependente do laço com o Outro primordial. 0 adoecimento e o subsequente tratamento médico é sempre vivido como uma situação de perda e de luto provocando sofrimento psíquico. Oferecemos nossa escuta para levar cada paciente a endereçar seu apelo ao psicanalista inserido no ambiente hospitalar e fazendo de sua fala o melhor recurso amortecedor frente ao desamparo. A prática da psicanálise aplicada na instituição hospitalar considera o paciente como sujeito do inconsciente. Por meio do desejo do analista é possível verificar os efeitos do inconsciente no discurso do sujeito, acrescentando ao saber médico sobre a doença a consideração pela subjetividade única de cada doente. 
A prática no hospital ensina sobre a dificuldade de cada um em experimentar o corpo como frágil e desamparado. Comportamentos disruptivos, alterados e inéditos acompanham a experiência de sofrimento, dor e sujeição às intervenções médicas. Reações emocionais exorbitantes, alterações do humor como crises de ansiedade, paranoia e insônia, alienação em relação ao diagnóstico de uma doença grave, recusa do tratamento hospitalar, aversão a uma série de medicações, crises de angústia, medo, temor e pânico podem constituir-se em desafios muito grandes à nossa formação como analistas. Essas são reações extremas recolhidas no cotidiano hospitalar e que apontam para um desaparelhamento do sujeito frente ao real da morte. Destacamos aqui as diferenças profundas entre a prática psicanalítica no hospital e seu exercício protegido no dispositivo analítico clássico em consultório privado.

A psicanálise aplicada à instituição hospitalar permite observar diretamente a experiência de luto. Esta experiência consiste no retorno da libido investida nos objetos amorosos e na realidade que nos cerca para uma parte do corpo ou mesmo para o próprio eu. Recordamos aqui a observação de Freud (1914) acerca do homem que sofre de dor de dentes e fica temporariamente incapaz de amar. Tudo se passa como se esse estado fosse uma espécie de narcisismo secundário. Precisamos distingui-lo do narcisismo secundário propriamente dito. Este último se caracteriza pelo retorno da libido objetal ao ego nos casos de psicose. Como o objeto do psicótico é simultaneamente um objeto de identificação e de amor, a perda do objeto vai levá-lo a identificarse ao objeto perdido. Embora não se trate de uma experiência psicótica, Freud destaca que na vida "normal" podemos experimentar situações em que a libido retroage do mundo externo para o ego, por exemplo, na doença orgânica e no processo de luto. A situação de doença e despedaçamento do corpo convoca o ego a retornar a libido objetal para si, como uma defesa narcísica frente a ameaça de perda da integridade da saúde. O sujeito doente é aquele completamente envolvido com as dores do corpo. Cada procedimento médico, exame, medicação, alteração de sintomas físicos e finalmente, a internação hospitalar, são situações em que o sujeito retorna toda a sua atenção para o próprio corpo, numa tentativa de recuperação narcísica de si.

A teoria do narcisismo ensina que os resíduos do narcisismo primário permanecem no psiquismo, mas estão recalcados (Freud, 1914). O sujeito doente já ocupou na vida infantil a posição narcísica do ego ideal para seus pais e, inconscientemente, busca retomar a posição de objeto de amor para o Outro. Este desejo recalcado não é aceitável para o ego, portanto, inaugura a divisão subjetiva entre o desejo inconsciente e as demandas da cultura e da civilização que requerem o abandono desta posição infantil. A situação de doença atualiza a posição objetificada, uma vez que o sujeito se torna novamente dependente de um outro que cuide dele, mas, diferentemente do que ocorre na vida infantil, no hospital o sujeito vive a situação de dependência como perda do seu valor e como ferida narcísica.

O ego representa o sujeito do enunciado pois é ele quem diz EU. O ego adulto é resultado da identificação ao ideal paterno e tem como funções a autopreservação, o gerenciamento da 
libido, a manutenção do recalque, além de ser responsável pelo "teste de realidade" e pelo controle da motilidade. Ainda assim, vinculado ao desejo inconsciente, recalcado no processo de identificação à função paterna e dividido no desejo. A divisão subjetiva é resultado do recalque e aponta para a impossibilidade de reencontro com o objeto perdido e com o narcisismo primário. De acordo com Lacan (1955-56), a função paterna advém do Outro da ordem simbólica, constituída pela linguagem e composta de elementos significantes formadores do inconsciente.

As características do ego de cada paciente na situação de internação fazem muita diferença no modo de enfrentar a experiência hospitalar. A maneira como cada um cuida de si e privilegia ou não sua saúde diz respeito à maior ou menor capacidade do eu de assegurar sua autopreservação e de alimentar o amor de si mesmo. As perdas vividas durante o tratamento hospitalar convocam o sujeito a responder com seu desejo de viver e se reinventar frente as perdas. $O$ ego não é o lugar da verdade do sujeito, mas sim o desejo inconsciente. Para além das funções que exerce na vida do sujeito, o ego é a imagem que ele tem de si mesmo. Na situação de adoecimento o ego manifesta comportamentos defensivos, o que the confere uma função fundamental, a luta pela preservação da vida. Identificar essas atitudes durante a abordagem do sujeito em situação de doença é primordial para a prática da psicanálise aplicada à instituição de saúde.

As experiências primitivas de satisfação ou de dor nos permite entender a origem dos afetos de prazer e desprazer e os estados de desejo, está vinculada à concepção freudiana de um desamparo original do ser humano. Ao contrário dos animais, o ser humano possui uma vida intrauterina de duração reduzida, somente nove meses, e nasce despreparado para a vida. Essa condição originária de fragilidade e despreparo em relação aos perigos do mundo externo o coloca numa total dependência em relação a pessoa responsável pelos seus cuidados, via de regra, a mãe. $O$ recém nascido não é capaz de prover sua sobrevivência, isso é excepcionalmente notável no caso das necessidades internas, como por exemplo, a fome.

No artigo Projeto Para uma Psicologia Científica, Freud (1895) apresenta sua hipótese acerca da estrutura do aparelho psíquico como um instrumento de regulação que providencia a descarga das excitações e busca alcançar o prazer e reduzir o desprazer. Esse funcionamento é particularmente notável no caso da fome, uma vez que a ação específica só pode ser realizada por auxílio de outra pessoa, a mãe. Assim, a eliminação da tensão interna causada por um estado de necessidade dá lugar à experiência de satisfação.

Desde então, a experiência de satisfação fica associada à imagem do objeto que possibilitou a satisfação, assim como a imagem do movimento que permitiu a sua descarga. Quando se repete um estado de necessidade, novamente esse padrão (imagem do objeto + imagem do movimento) é reinvestido, reproduzindo a situação de satisfação original. Porém, o que é reativado é o traço mnemônico da imagem do objeto, sem que essa reprodução venha acompanhada da presença real do objeto. O desejo em relação ao objeto faz surgir uma 
alucinação do objeto. Nesta situação, o recém nascido não consegue se distinguir do objeto na realidade. $\mathrm{O}$ objetivo do recém nascido é alcançar o reencontro com o objeto, associando o desejo pelo objeto + alucinação do objeto real. Entretanto, quando o objeto real não comparece, não está lá, a satisfação alucinatória vai se mostrar um engodo e o bebê se verá frustrado no seu desejo (Freud, 1895).

Freud (1985) diz que o mesmo mecanismo comparece na experiência de dor. Sabemos que uma das tendências mais fundamentais do aparelho psíquico é a de evitar o desprazer, que está associado ao excesso de excitações internas (Q). Assim que esse aumento ocorre, surge em resposta uma propensão à descarga e de imediato uma associação desta com a imagem do objeto que produz dor. Tal como no caso da experiência de satisfação, se a imagem do objeto hostil é reinvestida, surge então um estado de desprazer/dor acompanhado de uma forte tendência à descarga. Essas duas situações vão constituir os estados de desejos e os afetos.

Desde o Projeto (Freud, 1895), o ego é equivalente à consciência. Ele também aparece no artigo $A$ Interpretação dos Sonhos (Freud, 1900) como correspondente às definições metapsicológicas da primeira tópica do aparelho psíquico ${ }^{11}$. Veremos com o artigo Sobre 0 Narcisismo (Freud, 1914) como se dá o surgimento do ego no processo de constituição subjetiva e os resíduos remanescentes dessa etapa na vida adulta, especialmente na situação de adoecimento e tratamento hospitalar. Para alcançar esse esclarecimento, precisamos enfatizar a importância da relação primordial estabelecida entre a mãe e o bebê. A relação primária que a criança estabelece com a mãe, como aquela que garante a vida da criança e fornece experiências de satisfação, tem como resultado uma fixação pulsional. Se retomarmos o exemplo da fome, constataremos que a satisfação pulsional que acompanha a nutrição, através do ato de sugar o seio, cria uma nova forma de satisfação infantil.

A teoria acerca do desenvolvimento da libido está intimamente associada a maturação do corpo infantil. No decorrer do desenvolvimento fisiológico a experiência corpórea é vivida pela criança através das sensações do corpo como parcial, externo e desunificado. Em Três Ensaios sobre a Sexualidade Infantil , Freud (1905) diz que a sexualidade infantil é - perversa e polimorfa isso significa dizer que a criança vive sensações de prazer no corpo como parcial (fase oral, anal sádica e genital) e com a finalidade de satisfação própria, uma vez que não envolve o outro (por exemplo, o chuchar). A experiência de satisfação libidinal vivida no autoerotismo ${ }^{12}$, fase anterior ao narcisismo, e o corpo parcial e autoerótico é superado e apreendido como organismo único na fase do narcisismo e constituição do ego.

No artigo intitulado Sobre o Narcisismo, uma introdução, Freud (1914) refere-se à fase do narcisismo como a última etapa no desenvolvimento da libido infantil que desemboca na constituição do ego quando se funda um corpo próprio e unificado. O narcisismo primário faz alusão ao estado anteriormente descrito do recém-nascido entregue aos cuidados maternos, estado esse em que ele não poderia manter-se ao longo da vida, pois não permitiria nem a 
sobrevivência do indivíduo nem a propagação da espécie. Portanto, o narcisismo primário, enquanto realidade psíquica, precisa ser concebido apenas como o mito primário do regresso ao seio materno. O narcisismo primário é constituído somente como a projeção do amor dos pais pela criança. Na primeira infância ela é tratada como Sua Majestade, o Bebê (Freud, 1914). A criança ocupa a posição de pura perfeição e onipotência para os pais, sendo fonte de toda a atenção e objeto de todo o amor. A posição narcísica é de satisfação completa em si próprio. $O$ amor parental em relação ao filho produzirá o ego e, consequentemente, o amor de si mesmo, isto é, o narcisismo. A criança poderá amar a si própria da mesma maneira que foi amada pelos pais e 0 ego infantil será o reservatório da libido objetal e da libido do ego.

$\mathrm{Na}$ terceira parte do artigo Sobre o Narcisismo, Freud (1914) indaga sobre o que foi feito do narcisismo infantil. Ele aponta para o efeito do recalque como possível solução para essa dúvida. O recalque advém do ego, e tem a sua fonte nas exigências culturais e civilizatórias. Apesar dessas exigências serem externas e vinculadas à linguagem e à cultura, sabemos que nem todos os indivíduos reagem da mesma maneira a essas exigências. As mesmas experiências, impulsos, percepções e desejos podem afetar um sujeito de uma maneira e afetar outro de maneira distinta. A solução encontrada por Freud para descrever a fonte desse problema foi o conceito de ideal, que serve para explicar as diferentes identificações e idealizações para cada indivíduo. Assim, a formação de um ideal é fator condicionante do recalque (1914).

O narcisismo se desloca do ego real - infantil - para o novo ego ideal, narcísico, dotado de todas as perfeições. Assim, a criança é levada a se confundir com a fantasia narcísica advinda do narcisismo a que um dia seus pais tiveram que renunciar. Eles também foram incapazes de renunciar completamente à perfeição narcísica de sua infância e projetaram no filho essa expectativa de satisfação abandonada. Portanto, o ego infantil é constituído sob o imperativo de dever se tornar tudo aquilo que os pais não conseguiram ser, levar adiante os desejos insatisfeitos de seus pais, mais ainda, dar continuidade aos sonhos abandonados e dar sentido à própria existência dos pais no mundo.

Enquanto o ego ideal tem seu modelo no narcisismo primário, o ideal do ego tem seu modelo numa instância diferenciada, externa ao ego, resultante da convergência do narcisismo primário e da identificação com a figura parental. A diferenciação desses dois termos, ego ideal e ideal do ego, se explica pelo processo denominado por Freud de idealização. Temos duas identificações: a identificação narcísica primária, pré-edipiana, característica do ego ideal e a identificação narcísica secundária, a partir da função paterna, identificação ao Outro, característica do ideal do ego. Em Luto e Melancolia, Freud (1915) explica a identificação como uma reação à perda do objeto Ele diferencia a reação "normal" à perda do objeto como o processo de luto e a reação melancólica, como identificação maciça ao objeto.

No trabalho do luto, a libido obedece à realidade que the ordena renunciar a toda a libido investida no objeto, para tornar-se livre e retornar ao ego. Aqui, a libido objetal retorna ao ego de 
forma momentânea e posteriormente ela é reinvestida nos objetos do mundo externo, facilitando a elaboração da perda e o retorno dos elos em direção a vida. Na situação do luto a identificação com o objeto perdido é parcial, sendo vinculada a partes do objeto e não ao objeto como um todo. No caso da melancolia ocorre algo diferente, uma vez que a identificação ao objeto de amor é total. O ego se identifica ao objeto perdido e assim permite à libido prosseguir no seu investimento, internamente. $O$ objeto no lugar de ser abandonado é internalizado no ego, como parte do ego, mantendo a libido vinculada a ele. Portanto, o ego se torna, por identificação, o objeto ambivalente de amor e de ódio, resultando na clivagem do ego entre a faculdade crítica do ego e o próprio ego alterado pela identificação maciça (Freud, 1915).

A teoria freudiana acerca do ego sofre mudanças com a chamada "virada dos anos 1920" e reformulação do aparelho psíquico através do artigo Além do Princípio do Prazer (Freud, 1920). A introdução da teoria acerca do que há de mais pulsional na pulsão, a pulsão de morte, reformula a percepção acerca do ego. Entendemos que na segunda tópica do aparelho psíquico ${ }^{13}$, o ego freudiano está para além da diferenciação ego-inconsciente, pois há algo de pulsional e inconsciente no próprio ego. É importante ratificar que a introdução da dimensão pulsional no novo aparelho psíquico - id, ego, superego - não exclui a antiga formulação consciente/préconsciente/inconsciente. Os conceitos fundamentais que inauguraram a teoria freudiana continuam válidos e se somam à reformulação do aparelho psíquico de 1920.

No texto $O$ ego e o id (Freud, 1923), observamos alterações no conceito de ego, sob a perspectiva das capacidades dinâmicas e econômicas. A partir desse texto, o ego é responsável pelas funções de autopreservação, gerenciamento da libido, recalque, além de responsável pelo "teste de realidade" e pelo controle da motilidade. O ego como instância está em contato com dois mundos: o mundo interno e o externo. Ele é o mediador entre os desejos do id e o mundo externo, devido à sua posição privilegiada em relação ao sistema perceptivo e tende a atender às exigências do id sem causar conflitos com a realidade e com o mundo externo. Ele é dependente do id, pois é do id que ele retira a libido necessária para a sua própria manutenção. Portanto, o ego não é senhor de sua própria casa (Freud, 1923) e precisa atender a três senhores: o id, o superego e a realidade.

Compreender o desenvolvimento da teoria psicanalítica acerca do ego, desde a primeira tópica, com o texto do Projeto (Freud, 1895), passando pelo conceito de narcisismo (Freud, 1914), é fundamental para alcançar a noção de identificação a partir do conceito de ideal e, finalmente, entender as reformulações na segunda tópica (Freud, 1923), do ego pulsional enraizado no id.

O narcisismo primário revela a fragilidade do ego infantil e desamparado. $O$ investimento libidinal proveniente dos pais possibilita a nova ação psíquica - o amor de si e a unificação da imagem. A nova ação psíquica permite a unificação do corpo e da libido no ego e, consequentemente, o surgimento do sujeito que fala de si, ama a si próprio e se nomeia. A partir da identificação ao ideal externo, ideal a ser seguido, o ego internaliza a função paterna. Em 
consequência, ultrapassa o complexo de castração e o complexo de édipo, o que inaugura a sua entrada no laço social a partir da simbolização da diferença sexual. Nesse sentido, a teoria do narcisismo é o ponto chave para compreendermos os impasses vividos no tratamento hospitalar, considerando como cada estrutura subjetiva se comporta frente ao desamparo e como o sujeito se relaciona com a ameaça de castração, a partir do recalque.

$\mathrm{O}$ amor de si e a autoestima são relativos à fase do narcisismo primário. A criança ama a si própria da mesma forma que foi amada pelos pais, assim o ego infantil é correspondente ao lugar do objeto eleito. A saída da posição narcísica vem acompanhada de frustração e perda da posição de perfeição. A ferida narcísica é a perda do lugar de onipotência, o que direciona o sujeito para as leis e regras culturais e civilizatórias. O ego ideal não abdica da sua posição idealizada de majestade e se vê obrigado a prescindir desse lugar pelo reconhecimento de um novo ideal, agora externo a si. A entrada da função paterna abala a relação narcísica da criança com a mãe e inaugura o novo ideal a ser seguido.

Para concluir, queremos lembrar que a interdição do incesto e a supremacia fálica inauguram o complexo de castração e o complexo de édipo. Esse modelo é a base da sintomatologia analítica, a partir do laço social submetido às relações tradicionais de parentesco e às relações verticalizadas de hierarquia e autoridade na família e na cultura. $O$ sintoma é a forma singular que o sujeito cria para dar uma resposta ao conflito edípico e se inscrever na cultura. A psicanálise aplicada à prática institucional leva em consideração a formação sintomática de cada um e a forma inédita e singular que o sujeito encontra para se relacionar com o próprio corpo e com o Outro de cada um.

Nesse sentido, as vivências narcísicas são atualizadas durante o adoecimento e a libido objetal retorna para o ego, o que exige intervenção e escuta do psicanalista que atua no hospital. Por não estar incluído no discurso da ciência, essa manifestação subjetiva é compreendida como um desajuste aos protocolos hospitalares que fogem à hegemonia do conhecimento médico. As tentativas de acolhimento e suporte da equipe não parecem ser o suficiente para "tratar" as subjetividades. Esse momento inédito evidencia o confronto do sujeito do inconsciente, não-todo, faltoso, e os procedimento técnicos-científicos que visam tratar de forma objetiva e precisa qualquer sintoma.

\section{A clínica esclarecida pela teoria}

Para exemplificar trazemos uma breve vinheta clínica. R., de 62 anos, é casado, pai de dois filhos e engenheiro bem sucedido. Foi hospitalizado em situação de urgência, com o objetivo de realizar uma cirurgia em decorrência de uma obstrução intestinal aguda e permaneceu em estado grave, na UTI por quase 30 dias. Quando é despertado da sedação, R. se vê numa nova condição física, uma vez que está restrito ao leito, necessitando de auxílio respiratório e portando sondas urinária e nasogástrica. 
A nova condição de dependência emocional e física tem forte impacto no paciente. Para ele, acordar da sedação, perceber-se como um corpo fragilizado, fraco e dependente de cuidados, restrito ao leito, subordinado à rotina hospitalar, ocasiona uma angústia insuportável. Se a causa da internação e a doença que se estabeleceu, se o tratamento resolverá o problema de saúde, se as medicações serão suficientes para curá-lo e, se o corpo irá suportar tantas intervenções, são questões muito sérias, mas não são essas as suas preocupações. Na fala, nos pedidos de ajuda, na perda do sono, as manifestações emocionais de R. se concentram no sofrimento em se ver dependente de outros, seu corpo, sua vida, seus negócios, sua família, não é mais ele que rege isso tudo.

A repentina mudança na posição subjetiva foi traumática para o paciente. Era ele quem comandava os negócios e a família, portanto, ponto de sustentação e apoio de todos. Agora, doente, fraco e fragilizado, sente que deixou de ser o homem altivo, viril e provedor para ocupar uma posição passiva de submissão aos cuidados da equipe hospitalar. A partir da situação de adoecimento, ele se viu destituído da antiga identificação ao ideal do eu viril, papel que ele representava para si mesmo e para os outros. A imagem que R. tinha de si mudou, a identificação do sujeito ao ideal declinou e ele não se sente capaz de ultrapassar esse obstáculo. Está deprimido, ressentido, decepcionado consigo mesmo e com o outro.

A avaliação diagnóstica deste caso permitiu compreender a importância de seu pai como objeto de identificação na constituição do ideal do eu de R. Mais além do pai, havia também a grande admiração por seu avô. Deles, herdou o nome que portava orgulhoso. 0 pai e o avô lutaram em guerras para proteger a sua família e seu país: Guerra do Paraguai (avô), e Segunda Grande Guerra (pai). R. herdou o sentimento de dever moral e ético, sendo aquele que sempre deve desempenhar a sua melhor performance para enfrentar os piores impasses. Mas agora ele se via habitando um corpo que não respondia como antes ao seu comando pois perdeu grande parte de sua capacidade muscular. Apesar dessa condição, R. desejava melhorar e avançar no tratamento, como era o seu "dever", e por isso tinha dificuldades em considerar os limites impostos pela realidade. O paciente estava ferido narcisicamente, o ego idealizado e imaginariamente onipotente estava fragilizado. Havia risco de crise subjetiva, caso R. abandonasse os investimentos libidinais no mundo externo e também a realização dos ideais que sustentaram até então seu desejo e o sentido de sua existência.

O desejo de recuperar a posição perdida aparecia na sua fala diariamente: "eu tenho um plano e preciso cumpri-lo, etapa por etapa, pois depende só de mim e eu preciso conseguir dar o meu melhor todos os dias"(sic). Ele precisava nomear aquilo que havia perdido, a identificação ao ideal viril de força e vitalidade física. No lugar deste vieram as perdas no corpo: de massa muscular e da capacidade de equilíbrio. Passou a precisar de auxílio da fisioterapia para se manter em pé e se movimentar, além da submissão a uma rotina desagradável de cuidados da enfermagem: banhos no leito, trocas de fraldas, medicações e muito exames. 
A intervenção psicanalítica no momento de maior desesperança contribuiu para sustentar a ação psíquica de resgate do narcisismo ferido através de um novo investimento libidinal no ego. A presença do analista, sua escuta atenta dos significantes mais primordiais da história deste homem e suas intervenções precisas no sentido de barrar a passagem ao abandono, the permitiram superar as tentações da pulsão de morte. Somente assim, o ego frágil e desamparado pode se reconstituir, se fortalecer e então reinvestir em si mesmo e posteriormente na realidade. 0 trabalho da psicanálise aplicada ao hospital possibilitou a leitura cuidadosa deste caso, privilegiando resgatar a posição subjetiva perdida perante a vida. As identificações que sustentam um sujeito na vida podem sofrer abalos vigorosos frente a ameaça de perda, doença e morte. As manifestações do ego em face deste sofrimento podem levá-lo a abandonar-se. Pensar a lógica de cada caso é o que possibilita a identificação do ponto de angústia para cada um, considerando a singularidade e a particularidade subjetiva, para poder sustentar o desejo de viver e aliar-se às melhores reservas narcísicas que pudermos encontrar.

\section{Conclusão:}

O caminho percorrido através da prática hospitalar com pacientes em situação de urgência subjetiva traz indagações sobre o narcisismo e a incidência do imaginário frente ao real da doença e da morte como eventos sempre muito difíceis de elaborar completamente. Aprendemos com a teoria do narcisismo que o ego é orientado para o laço social através do ideal. Na situação crítica da doença aguda, o sujeito é convocado a agir em nome da vida e se valer da dimensão do ideal internalizada no ego. A estrutura subjetiva mediada pelo recalque permite que o sujeito seja capaz de se responsabilizar pelo seu corpo e sua saúde, tanto quanto oferecer um destino mediado pelo simbólico à ferida narcísica, através do processo de luto e reestruturação subjetiva. O processo de elaboração do luto se torna possível pela presença do psicanalista no cenário hospitalar como aquele que faz valer o lugar do sujeito como sujeito do inconsciente e acolhe a discursividade subjetiva como ferramenta para o diagnóstico e intervenções precisas, considerando a particularidade de cada um.

Partimos da constatação de que a psicanálise aplicada é uma prática que se orienta para o real e que considera na sua avaliação o ponto de enunciação do sujeito em relação à sua doença e ao seu sintoma. Testemunhamos que é a partir da urgência médica que se procura um hospital, portanto, o psicanalista na instituição considera que o campo de tratamento não está direcionado para o sintoma subjetivo e sim para o orgânico. Nesse sentido, o laço transferencial típico da clínica clássica, não está direcionado ao psicanalista, mas à instituição hospitalar. Cabe ao psicanalista interpretar a demanda, a partir do ato analítico e assim sustentar a urgência subjetiva que pode advir a partir do desejo do analista. Para isso, é preciso identificar o impasse subjetivo, a divisão do sujeito e as manifestações inconscientes num ambiente criado para ser estéril a qualquer manifestação subjetiva. Ou seja, identificar na escuta o que foge à lógica, à 
comunicação, à linguagem compartilhada, tal como os lapsos, os trocadilhos e os atos falhos. A partir da escuta do inconsciente, a urgência subjetiva pode advir durante a urgência médica. Cabe ao analista sustentar o ato analítico para que o sujeito se responsabilize pelo pela parte que lhe cabe no seu sofrimento.

\section{Notas:}

1. Este artigo é baseado na dissertação de mestrado de Manuella Itapary Ribeiro Moreira no Programa de Pós-graduação em teoria psicanalítica/PPGTP/UFRJ, sob orientação da profa. Dra. Tania Coelho dos Santos, intitulada $O$ narcisismo e a pós-modernidade: considerações freudianas acerca da constituição do eu, defendida em 2018.

2. Sonda passada do nariz até o intestino. Indicada para os pacientes que apresentam dificuldade na deglutição ou não possam se alimentar por via oral. Além disso, é aplicada para outras finalidades, como para a preparação de cirurgias, e em procedimentos diagnósticos e terapêuticos.

3. Indicada para realizar a drenagem urinária em pacientes com distúrbios urológicos.

4. Cateter venoso central de inserção periférica de longa permanência (PICC). Indicada para pacientes em uso de terapia intravenosa com drogas vasoativas.

5. Gastrostomia. Procedimento cirúrgico para a fixação de uma sonda alimentar.

6. Intubação endotraqueal (IOT). Procedimento de suporte avançado de vida indicado para preservar as vias aéreas de um paciente em insuficiência respiratória, oxigenação inadequada ou com depressão do nível de consciência.

7. Perturbação súbita, flutuante e reversível da função mental.

8. O conceito de Outro foi desenvolvido pelo psicanalista Jacques Lacan para referir-se às relações significativas da primeira infância (rede elementar de parentesco) até o Outro generalizado no sentido da sociedade, da cultura e do universo simbólico onde se insere um sujeito.

9. Na psicanálise, a transferência ocorre na relação entre paciente e psicanalista. Nela, o desejo do paciente, advindo de sua infância, e as relações primárias com as figuras parentais são atualizadas na relação com o psicanalista no decorrer do tratamento.

10. Projeto para uma psicologia científica (Freud, 1895).

11. Construções teóricas desenvolvidas entre os de 1900 até 1920.

12. Fase anterior e preparatória para o narcisismo primário. 0 autoerotismo corresponde a experiência de satisfação vivida através do próprio corpo, em que as partes do corpo correspondem a representações psíquicas de objetos de satisfação. A pulsão é dirigida para o próprio corpo e não para objetos do mundo externo.

13. Formulações freudianas acerca do aparelho psíquico, a partir da teorização da pulsão de morte, como o mais além do princípio do prazer. 


\section{Referências Bibliográficas}

Coelho dos Santos, T. (2001). Quem precisa de análise hoje? discurso analítico: novos sintomas e novos laços sociais. Rio de Janeiro: Bertrand Brasil.

Coelho dos Santos, T. (2005) Sinthoma: corpo e laço social. Rio de Janeiro: Sephora/UFRJ.

Coelho dos Santos, T. (2005) A psicopatologia psicanalítica de Freud à Lacan. In Revista Pulsional de Psicanálise, vol. 18, n. 183, 74-81. São Paulo: Escuta.

Coelho dos Santos, T. (2005). A prática lacaniana na civilização sem bússola. In Coelho dos Santos (org.), Efeitos terapêuticos da psicanálise aplicada (pp. 61-92). Rio de Janeiro: Contra Capa.

Coelho dos Santos, T. (2014). Responsabilidade coletiva ou responsabilidade subjetiva: a saúde é um direito ou um dever? In: Barros R. M. \& Anciães V (orgs.). Psicanálise e saúde: entre $o$ sujeito e o Estado (pp. 159-180). Rio de Janeiro: Cia de Freud.

Cottet, S. (2005) Efeitos terapêuticos psicanalíticos na clínica contemporânea. In Coelho dos Santos, T. (org.), Efeitos terapêuticos na psicanálise aplicada (pp. 11-40). Rio de Janeiro: Contra Capa.

Cunha, L. H. C.S. (2010). A desinserção do campo da subjetividade na experiência de trabalho de profissionais de saúde. In Revista aSHEPallus de Orientação Lacaniana. Número 11, 177-193. Rio de Janeiro.

Freud, S. (1996). Edição standard brasileira das obras psicológicas completas de Sigmund Freud (Vol. I, pp. 333-454) Projeto para uma psicologia científica. Rio de Janeiro: Imago (trabalho original publicado em 1895).

Freud, S. (1996). Edição standard brasileira das obras psicológicas completas de Sigmund Freud (Volumes IV e V, pp.15-700) A interpretação dos sonhos. Rio de Janeiro: Imago (trabalho original publicado em 1900).

Freud, S. (1996). Edição standard brasileira das obras psicológicas completas de Sigmund Freud (Vol. 12, pp. 125-133) Recomendações aos médicos que exercem a psicanálise. Rio de Janeiro: Imago (trabalho original publicado em 1912).

Freud, S. (1996). Edição standard brasileira das obras psicológicas completas de Sigmund Freud (Vol. XIX, pp. 75-108) Sobre o narcisismo: uma introdução. Rio de Janeiro: Imago (trabalho original publicado em 1914).

Freud, S. (1996). Edição standard brasileira das obras psicológicas completas de Sigmund Freud (Vol. XIX, pp. 165-222) O inconsciente. Rio de Janeiro: Imago (trabalho original publicado em 1915).

Freud, S. (1996). Edição standard brasileira das obras psicológicas completas de Sigmund Freud (Vol. XIX, pp. 243-266) Luto e melancolia. Rio de Janeiro: Imago (trabalho original publicado em 1917). 
Freud, S. (1996). Edição standard brasileira das obras psicológicas completas de Sigmund Freud. (Vol. XIX, pp. 15-79). O Ego e o Id. Rio de Janeiro: Imago (trabalho original publicado em 1923).

Freud, S. (1996). Edição standard das obras completas de Sigmund Freud. (Vol. 21, pp. 65-148) 0 mal-estar na civilização. Rio de Janeiro: Imago (trabalho original publicada em 1930[1929]).

Lacan, J. (2010). O Seminário. Livro 3: As psicoses. Rio de Janeiro: Jorge Zahar. (trabalho original publicado em 1955-56).

Lacan, J. (1998) O estádio do espelho como formador da função do eu (pp. 96-103). In: J. Lacan, Escritos, Rio de Janeiro: Zahar. (trabalho original publicado em 1998).

Saboya, F., Rieffel, E., Costa, F., Medrado, M. (2014). O papel do psicólogo junto aos familiares. In: Kitajima, K. (Org.). Psicologia em unidade de terapia intensiva: critérios e rotinas de atendimento (pp. 23-36). Rio de Janeiro: Revinter.

Saboya, F., Itapary, M. (2017). Da urgência médica à urgência subjetiva: a responsabilidade institucional e a responsabilidade de cada um. In: Saboya, F. (Org.). Psicologia em unidade de terapia intensiva: intervenções em situações de urgência subjetiva (pp. 35-44). Rio de Janeiro: Atheneu.

Citação/Citation: Itapary Ribeiro Moraes, M. \& Coelho dos Santos, T. (mai. 2019 a out. 2019). Psicanálise aplicada à instituição: a prática clínica no hospital geral. Revista aSEPHallus de Orientação Lacaniana, 14(28), 125-140. Disponível em www.isepol.com/asephallus. Doi: 10.17852/1809709x.2019v14n28p125-140

Editor do artigo: Tania Coelho dos Santos.

Recebido/Received: 02/08/2019 / 08/02/2019.

Aceito/Accepted: 04/10/2019 / 10/04/2019.

Copyright: (c) 2019 Associação Núcleo Sephora de Pesquisa sobre o moderno e o contemporâneo. Este é um artigo de livre acesso, que permite uso irrestrito, distribuição e reprodução em qualquer meio, desde que o autor e a fonte sejam citados/This is an open-access article, which permites unrestricted use, distribution, and reproduction in any medium, provided the author and source are credited. 